\title{
Investigation of the North Brazil Current retroflection and North Equatorial Countercurrent variability
}

\author{
Carlos A. Fonseca, ${ }^{1}$ Gustavo J. Goni, ${ }^{2}$ William E. Johns, ${ }^{3}$ and Edmo J. D. Campos ${ }^{4}$ \\ Received 22 March 2004; revised 20 August 2004; accepted 8 October 2004; published 5 November 2004.
}

[1] Eight years of TOPEX/Poseidon altimeter-derived sea height anomaly and climatological hydrographic data are used to investigate the temporal and spatial variability of the North Brazil Current (NBC) retroflection and the North Equatorial Countercurrent (NECC). The NBC retroflection exhibits a mean position of $6.6^{\circ} \mathrm{N} \pm 2.0^{\circ}$, with a strong annual signal and year-to-year variability. The annual cycle of its location follows the meridional migration of the ITCZ and the strength of the wind stress curl over the equatorial Atlantic. A marked shift in the annual mean location of the NBC retroflection is observed in 1998-1999 that appears to be linked to an increase in wind stress curl during this period. The mean latitude of the NECC is estimated to be $6.0^{\circ} \mathrm{N} \pm 1.3^{\circ}$, with a semiannual cycle showing maximum northerly locations in February and August. The baroclinic transport of the NECC varies predominantly on an annual cycle with maximum transport of $12 \mathrm{~Sv}$ occurring in November. INDEX TERMS: 4231 Oceanography: General: Equatorial oceanography; 4275 Oceanography: General: Remote sensing and electromagnetic processes (0689); 4512 Oceanography: Physical: Currents; 4576 Oceanography: Physical: Western boundary currents; 4520 Oceanography: Physical: Eddies and mesoscale processes. Citation: Fonseca, C. A., G. J. Goni, W. E. Johns, and E. J. D. Campos (2004), Investigation of the North Brazil Current retroflection and North Equatorial Countercurrent variability, Geophys. Res. Lett., 31, L21304, doi:10.1029/ 2004GL020054.

\section{Introduction}

[2] Most cross-equatorial flows occur via three mechanisms: western boundary currents [Nof, 1996] such as the NBC; eddies associated with these currents [Johns et al., 1990, 1998; Goni and Johns, 2001]; and subtropical cells [McCreary and $\mathrm{Lu}, 1994]$. These cross-equatorial flows are closely associated with the strong northward heat flux in the Atlantic and, consequently, have a direct influence on the global heat budget [Philander and Pacanowski, 1986]. Therefore, the correct knowledge of the climatological fields and variability of the location and transport of these currents is necessary to aid in the understanding of the heat and mass balances associated with this current system.

\footnotetext{
${ }^{1}$ Cooperative Institute for Marine and Atmospheric Studies, University of Miami, Miami, Florida, USA.

${ }^{2}$ Atlantic Oceanographic and Meteorological Laboratory, Physical Oceanography Division, NOAA, Miami, Florida, USA.

${ }^{3}$ Division of Meteorology and Physical Oceanography, Rosenstiel School of Marine and Atmospheric Science, Miami, Florida, USA.

${ }^{4}$ Laboratório de Modelagem de Processos Oceânicos, Instituto Oceanográfico da Universidade de São Paulo, São Paulo, Brazil.
}

Copyright 2004 by the American Geophysical Union. 0094-8276/04/2004GL020054\$05.00
[3] In the tropical Atlantic, the spatial structure and transport of the surface currents reflects a response to the variation of the wind stress field. The main characteristic of the wind field is the migration of the Intertropical Convergence Zone (ITCZ), which reaches its northernmost position between July-September and its southernmost position in February-April [Waliser and Gautier, 1993]. Between July and February, the surface layer of the NBC separates from the coast at around $7^{\circ}-8^{\circ} \mathrm{N}$ and retroflects with its waters feeding the North Equatorial Countercurrent (Figure 1), in a process known as North Brazil Current retroflection (NBCR). During this process anticyclonic rings are shed, and then translate in the northwest direction [Johns et al., 1990]. From March through June, it is speculated that most of the NBC continues northwestward on the continental slope off the coast of the South America, eventually entering in the Caribbean Sea through the passages of the Lesser Antilles [Johns et al., 1998]. However, NBC eddies are still observed to translate in this region during this period of time [Goni and Johns, 2001].

[4] The NBC and the North Equatorial Current (NEC) feed the NECC, which flows eastward between $3^{\circ}-10^{\circ} \mathrm{N}$ across the tropical Atlantic and between two westward flows, the northern branch of the South Equatorial Current (SEC) and the NEC. Some studies indicate that during the boreal summer, when the ITCZ is located at its northernmost position, the maximum velocities in the eastward flow of the NECC are observed [Richardson and Reverdin, 1987]. During the spring, when the ITCZ is located at its southernmost location, the NECC becomes weak and may be replaced by a westward flow [Garzoli and Katz, 1983; Garzoli and Richardson, 1989].

[5] The objective of this work is to investigate the spatial and temporal variability of the NBCR and NECC using a combination of altimetry and climatological hydrographic data for an 8-year period between 1993 and 2000. Some of the results obtained here are also correlated with remote wind field parameters derived from satellite observations in the tropical Atlantic.

\section{Data Sets}

[6] Four data sets are used in this study: 1) T/P altimeter-derived sea height anomaly (SHA). The 9-km along track SHA values are used to construct daily SHA and sea height residual (SHR) fields every 10 days in a $0.5^{\circ}$ grid, using a Gaussian interpolator of radius $0.75^{\circ}$. The SHR fields are obtained by extracting the mean monthly signal from the SHA fields. 2) Climatological annual fields of the depth of the $20^{\circ} \mathrm{C}$ isotherm and of the reduced gravity [Conkright et al., 1998], which are com- 


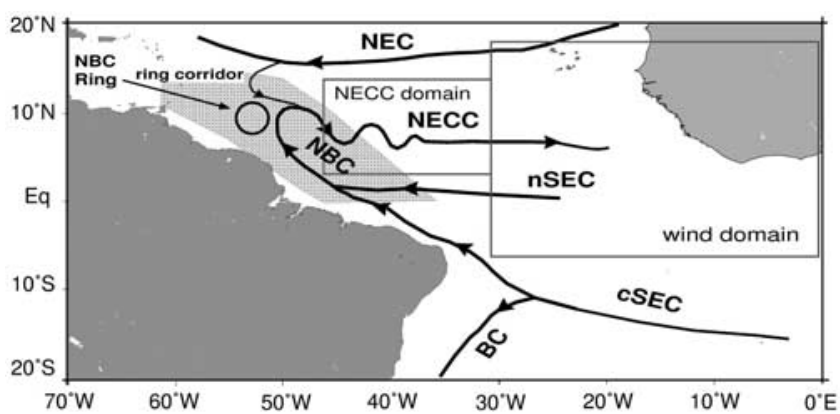

Figure 1. Schematic showing the main surface currents in the study region in the Atlantic: NBC, the Brazil Current (BC), the central and northern branch of the SEC (cSEC and nSEC, respectively), the NECC, and the NEC. The boxes show the domains where the wind parameters and the NECC parameters were calculated. The shaded area is the NBC ring corridor.

bined with the SHA to create fields of upper layer thickness [Goni and Johns, 2001]. 3) Climatological annual dynamic heights relative to $1000 \mathrm{~m}$ depth level in a $1^{\circ}$ grid [Levitus et al., 1994; Levitus and Boyer, 1994]. They are combined with the SHA data to construct fields of the dynamic height. 4) Monthly wind fields derived from the European Remote Sensing (ERS) Scatterometer. These fields are computed in a region bounded by $6^{\circ} \mathrm{S}-$ $16^{\circ} \mathrm{N}$ and $0^{\circ}-30^{\circ} \mathrm{W}$ (Figure 1) and are used to calculate the wind stress curl, from which the position of the ITCZ in the tropical Atlantic is estimated.

\section{NBC Retroflection}

[7] Most of the variability of the sea surface height in the NBC region is due to the motion of the NBCR, generation and translation of $\mathrm{NBC}$ rings and eddies, and to steric effects. The spatial and temporal variability of the NBCR is investigated here in terms of its northernmost location. The methodology to identify rings and the NBCR front in this region is described by Goni and Johns [2003]. The position of the NBCR is placed at the northernmost location of the zero SHR contour occurring within a region of positive SHA between $0^{\circ}$ to $12^{\circ} \mathrm{N}$. This method provides an estimate of the location of the NBCR that is independent of the annual signal produced by the steric effects. In addition, upper layer thickness maps were used to aid in differentiating the retroflection from the rings.

[8] In general, the NBCR location cannot be identified during the months of April through June, which corresponds to the weak or absent phase of the retroflection [Didden and Schott, 1993]. Our results show that the northernmost location of the NBCR ranges between approximately $1^{\circ} \mathrm{N}$ and $11^{\circ} \mathrm{N}$ (Figure 2a). The mean location of the NBCR is $6.7^{\circ} \mathrm{N} \pm 1.8^{\circ}$ with a strong year-to-year variability (Figure 2b). The rapid extension and retraction of the NBCR on a time scale of several months found here may correspond to Rossby waves that are generated from an unstable NECC [Jochum and Malanotte-Rizzoli, 2003]. This behavior of the NBCR is supported by independent inverted echo sounder (IES) observations, which show that these motions are associated with the shedding of NBC rings [Garzoli et al., 2003]. The monthly means of the altimeter-derived location of the NBCR (Figure 3a) show that the southernmost and the northernmost location both occur during the summer (July and August, respectively), associated with the onset phase of the retroflection. The rms of the monthly mean values is nearly constant, at approximately $1.5^{\circ}$, which is consistent with independent evidence that there may not be a preferred season for NBC ring formation [Goni and Johns, 2003]. On longer time scales, interannual variability of the NBCR is indicated by a more southerly mean location during the period 19931996 and a more northerly location during 1998-1999. The mean NBCR location during the 1993 through 1996

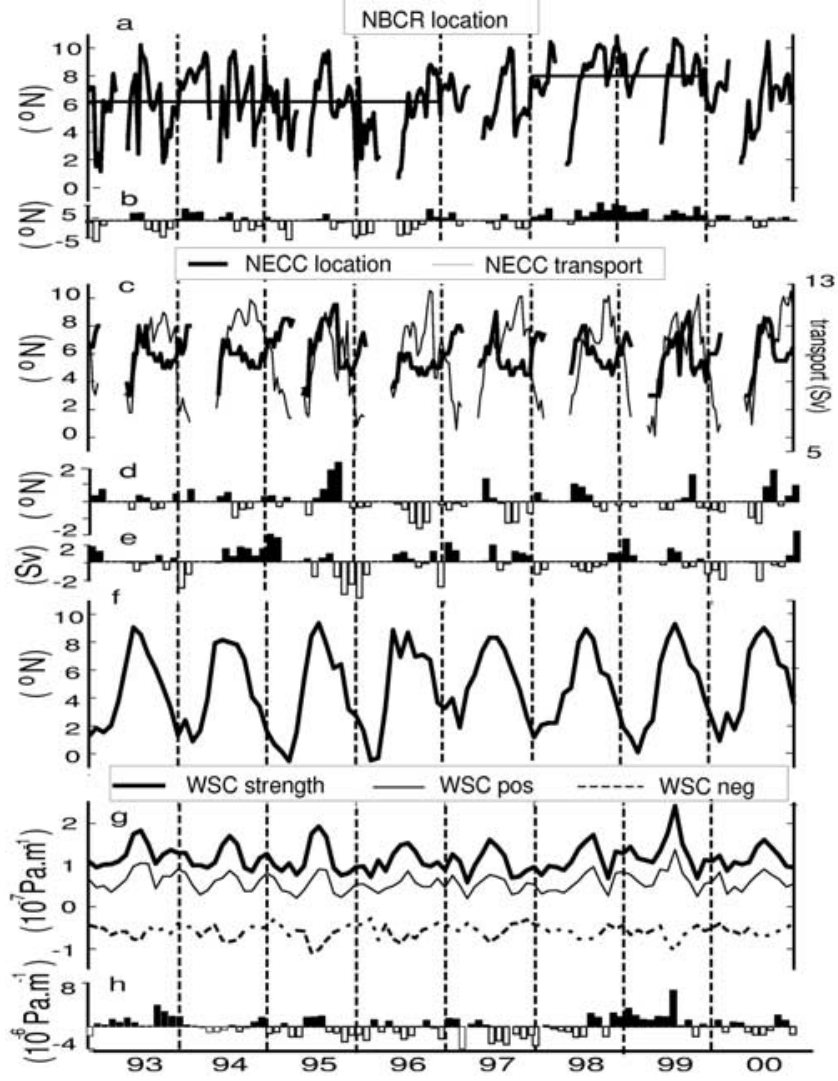

Figure 2. (a) Time series of the northernmost location of the NBC retroflection. The horizontal lines are the mean values for the periods 1993-1997 and 1998-1999, (b) monthly anomalies of the northernmost location of the NBC retroflection relative to the climatological annual cycle for 1993-2000, (c) time series of the location of the NECC (thick line) and the transport of the NECC (thin line), ( $\mathrm{d}$ and e) monthly anomalies of the NECC location and transport, respectively, (f) time series of the location of the ITCZ, (g) time series of wind stress curl (WSC) values in the tropical Atlantic: maximum positive WSC (thin line), maximum negative WSC (dashed line), and their difference (thick line) and (h) monthly anomalies of the difference between maximum positive and maximum negative WSC. 


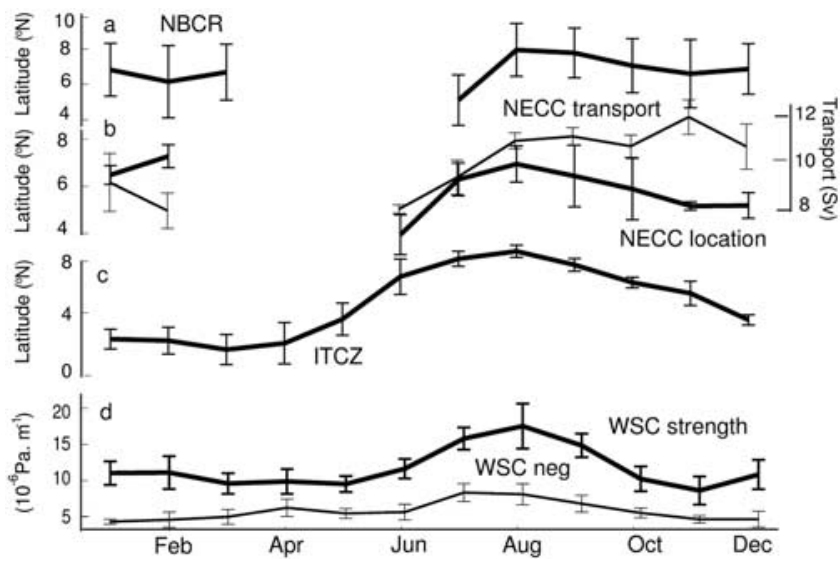

Figure 3. Monthly means, between 1993 and 2000, of (a) the northernmost location of the NBC retroflection (NBCR), (b) the location (thick line) and the transport (thin line) of the NECC, (c) the ITCZ location and (d) WSC strength (thick line) and maximum negative WSC (thin line). The bars indicate the rms values.

is $6.1^{\circ} \mathrm{N} \pm 1.7^{\circ}$, and during the 1998 through 1999 it is $8.1^{\circ} \mathrm{N} \pm 1.6^{\circ}$ (Figure 2a).

\section{North Equatorial Countercurrent}

[9] Although partly fed by the NBC, the NECC exhibits its own characteristic seasonal cycle [Richardson et al., 1992]. The spatial and temporal variability of the location of the NECC is investigated here using dynamic height fields obtained by adding the T/P-derived SHA fields to the annual mean dynamic height field. The position of the core of the NECC is defined as the location of the maximum meridional gradient of dynamic height in the region limited by $30^{\circ}-45^{\circ} \mathrm{W}$ and $2^{\circ}-12^{\circ} \mathrm{N}$ (Figure 1 ). The strength of the NECC is computed as follows: first, the zonal mean of the dynamic height field is calculated; second, the meridional gradient of this zonally-averaged dynamic height profile is computed; third, the position of the maximum gradient is identified; and fourth, using this location, the mean value of the gradient of the dynamic height over $2^{\circ}$ of latitude centered at the position of the maximum gradient is computed. This gradient, defined here as the NECC strength, is proportional to its geostrophic velocity and transport [Katz, 1993].

[10] Results obtained here show that the core of the NECC is approximately confined between $3^{\circ}-10^{\circ} \mathrm{N}$ during 1993-2000 (Figure 2b), with a mean location of $6.0^{\circ} \mathrm{N} \pm 1.3^{\circ}$, approximately $1^{\circ}$ to the south of the mean northernmost position of the NBCR during the same period of time. Previous studies using IES along $28^{\circ} \mathrm{W}$ at $0^{\circ}, 3^{\circ}, 6^{\circ}$ and $9^{\circ} \mathrm{N}$ during 1983 and 1984 showed that the NECC was located between $3^{\circ}$ to $9^{\circ} \mathrm{N}$ [Garzoli and Richardson, 1989]. Historic ship-drift data also show the core of the NECC is between $3^{\circ}$ and $10^{\circ} \mathrm{N}$ between $35^{\circ}$ to $45^{\circ} \mathrm{W}$ [Richardson and McKee, 1984]. Our results show that the location of the NECC exhibits two maxima (northernmost location), in February and August, and two minima (southernmost location), in June and December, which is indicative that its motion has a semiannual component. The rms of the mean monthly location of the NECC (Figure 3b) ranges from approximately $0.5^{\circ}$ (November) to $3^{\circ}$ (September). The low values of $\mathrm{rms}$ in November could be a consequence of the narrowing of the NECC observed earlier in ship-drift data [Richardson and McKee, 1984].

[11] The NECC strength exhibits large variability, with values ranging from 0 to $8.5 \mathrm{~cm} /{ }^{\circ}$ lat. Values less than $1.3 \mathrm{~cm} /{ }^{\circ}$ lat were not used to identify the NECC because of the difficulties in determining the location of maximum gradient for low gradient values. This index of the NECC strength is then used to estimate the transport of the NECC based on an empirical expression for the geostrophic transport of the NECC using the difference of dynamic height $(\Delta \mathrm{h})$ across the current $[\mathrm{Katz}, 1981]$ :

$$
\operatorname{Transport}(S v) \cong 4.2^{*} \sqrt{\Delta h(\mathrm{~cm})} .
$$

[12] The transport of NECC (Figure 2b) calculated from this expression varies from approximately 6 to $12 \mathrm{~Sv}$. Maximum values of transport, associated with locations of the core at about $5^{\circ} \mathrm{N}$, usually occur during OctoberNovember, in good agreement with previous studies using XBT data at $28^{\circ} \mathrm{W}$ [Richardson et al., 1992]. The mean monthly values of the transport of the NECC (Figure $3 b$ ) show the same qualitative characteristics as the time series of the baroclinic transport estimates using hydrographic XBT data, with maximum monthly values ranging from 7 to $12 \mathrm{~Sv}$. In the mean, the NECC is observed to be weaker during the first half of the year and stronger during October and November.

[13] Power density spectra results (not shown) indicate that the motion of NECC has a dominant semiannual period, while its transport has a dominant annual period. The relationship between the transport and the location of the NECC core shows interesting features (Figures $2 b$ and $3 b$ ). During the onset phase of the NECC in June-August, both the strength and location of the NECC increase in tandem, and then the current shifts southward while its strength continues to increase. The maximum strength of the NECC occurs at about the time of the fall minimum in its location (on average in November). The NECC location then moves northward again as the NECC strength diminishes in winter.

[14] Interannual anomalies in the NECC location and strength do not show any persistent patterns or obvious correlation over the period investigated; however, during certain years both the location and strength show significant anomalies relative to their climatological values. For example, the monthly anomalies of the NECC location were atypically far north (south) in 1995 (1996), and the monthly anomalies of the NECC transport were unusually strong (weak) in 1994 (1995).

\section{The NBCR, NECC and the Wind Field}

[15] Four wind stress parameters were derived from ERS scatterometer winds in the latitude range $6^{\circ} \mathrm{S}-16^{\circ} \mathrm{N}$ outside from NBCR/NECC region in a attempt to see any links to remote forcing of this system: a) the minimum value of zonally averaged wind stress curl (WSC), (b) the maximum value of zonally averaged WSC, (c) the difference between 
these maximum and minimum WSC values, and d) the position of the ITCZ, which is placed at the location of the zero of the WSC. Spectra of these time series (not shown) indicate that the negative WSC is dominated by the annual cycle while the dominant variability of the positive WSC is semiannual. Therefore, the WSC difference has a mixed annual-semiannual cycle (Figure $3 \mathrm{~d}$ ). The ITCZ cycle is annual with its northernmost location at $9^{\circ} \mathrm{N}$ in August and southernmost location at $1^{\circ} \mathrm{N}$ in March.

[16] The minimum WSC (maximum negative WSC) is located south of the ITCZ and drives a seasonally varying, large-scale anticyclonic circulation comprised of the westward flowing SEC, northward flowing NBC, and eastward flowing NEC. The maximum in the negative WSC occurs in July and is closely followed by the maximum northerly location of the NBCR in August (Figure 3a), suggesting that the location of the NBCR is related to the transport of the NBC, which also peaks in August [Johns et al., 1998].

[17] The maximum strength of the NECC occurs later, during the fall (October-November), which is related to the influence of the positive WSC north of the ITCZ. The strength of the NECC should be influenced by both the negative WSC south of the ITCZ and positive WSC north of the ITCZ, and hence their difference. The peak in positive WSC occurs in September (not shown) and leads to an overall peak in the WSC difference in August (Figure 3d). The several month lag of the NECC transport to this cycle is consistent with expected delays due to Rossby wave propagation at this latitude [e.g., Garzoli and Katz, 1983].

[18] The August northernmost location of the NECC (Figure $3 b$ ) coincides with the northernmost location of the ITCZ, suggesting that the location of this current during this season is wind-driven, confirming previous results obtained using inverted echo sounders, drifters, current meters and ship-drifts [Richardson and McKee, 1984; Richardson and Reverdin, 1987; Garzoli and Richardson, 1989]. The location of the NECC closely follows the annual migration of the ITCZ except during winter (February), when it exhibits a secondary northward maximum while the ITCZ is still approaching its most southerly location. The reasons for this are unclear, although it may occur because the NECC becomes mainly supplied from the north at this time by the recirculation from the NEC, while its transport is reduced due to minor contribution from the NBC retroflection. These main features show some details about the variability of the NBCR/NECC system important to a better understanding of the equatorial and cross-equatorial mass and heat exchanges. These results can also be used to validate numerical models in the Tropical Atlantic region.

[19] Correlations between the wind stress and other derived parameters on interannual time scales are found to be statistically insignificant for the relatively short length of the time series considered here. However, it is noteworthy that the anomalous northward NBCR location during 1998-1999 coincides with an increase in the strength of the WSC during this same period (Figure 2). Goni and Johns [2003] also report an increase in frequency of NBC ring formation during this period. Numerical modeling results have proposed that this long period wind variability is linked to warm and cold events in the tropical Atlantic [Góes and Wainer, 2003], that impact the strength of the tropical Atlantic circulation. We speculate that the shift in the location of the NBCR may be due to an increase in the SEC and NBC transports driven by the wind stress curl. However, further analysis and availability of longer time series will be necessary to distinguish the important relationships between these current systems and the wind field on interannual time scales.

[20] Acknowledgments. This work was supported by Conselho Nacional de Pesquisa e Desenvolvimento), by the Inter-American Institute for Global Changes Research, and by Fundação de Amparo e Pesquisa do Estado de São Paulo (FAPESP). The first author acknowledges the support given by FAPESP through a M.Sc. fellowship. This work was also supported by NOAA/AOML and by NSF through the North Brazil Current Rings Experiment. Special thanks to Dr. Silvia Garzoli for her suggestions and for making possible the visit of the first author to the NOAA/AOML. Dr. Robert Cheney (NOAA/NESDIS) provided the altimeter data. The authors are thankful to the reviewers for their valuable comments.

\section{References}

Conkright, M. E., et al. (1998), World Ocean Database 1988, NOAA Atlas NESDIS [CD-ROM], Natl. Oceanic and Atmos. Admin., Silver Spring, $\mathrm{Md}$

Didden, N., and F. Schott (1993), Eddies in the North Brazil Current retroflection region observed by GEOSAT altimetry, J. Geophys. Res., 98, 20,121-20,131.

Garzoli, S. L., and E. J. Katz (1983), The forced annual reversal of the Atlantic North Equatorial Countercurrent, J. Phys. Oceanogr., 13, $2082-$ 2090 .

Garzoli, S. L., and P. L. Richardson (1989), Low frequency meandering of the North Equatorial Countercurrent, J. Geophys. Res., 94, 20792090 .

Garzoli, S. L., A. Ffield, and Q. Yao (2003), North Brazil Current rings and the variability in the latitude of the retroflection, in Interhemispheric Water Exchange in the Atlantic Ocean, Elsevier Oceanogr. Ser., vol. 68, edited by G. J. Goni and P. Malanotte-Rizzoli, pp. 357-373, Elsevier Sci., New York.

Góes, M., and I. Wainer (2003), Equatorial currents transport changes for extreme warm and cold events in the Atlantic Ocean, Geophys. Res. Lett., 30(5), 8006, doi:10.1029/2002GL015707

Goni, G. J., and W. E. Johns (2001), A census of North Brazil Current rings observed from TOPEX/POSEIDON altimetry: 1992-1998, Geophys. Res. Lett., 28, $1-4$.

Goni, G. J., and W. E. Johns (2003), Synoptic study of warm rings in the North Brazil Current retroflection using satellite altimetry, in Interhemispheric Water Exchange in the Atlantic Ocean, Elsevier Oceanogr. Ser., vol. 68, edited by G. J. Goni and P. Malanotte-Rizzoli, pp. 335-356, Elsevier Sci., New York.

Jochum, M., and P. Malanotte-Rizzoli (2003), On the generation of North Brazil current rings, J. Mar. Res., 61, 147-162.

Johns, W. E., T. N. Lee, F. A. Schott, R. Zantopp, and R. H. Evans (1990), The North Brazil Current retroflection: Seasonal structure and eddy variability, J. Geophys. Res., 95, 22,103-22,120.

Johns, W. E., T. N. Lee, R. C. Beardsley, J. Candela, R. Limeburner, and B. Castro (1998), Annual cycle and variability of the North Brazil Current, J. Phys. Oceanogr., 28, 103-128.

Katz, E. J. (1981), Dynamic topography of the sea surface in the equatorial Atlantic, J. Mar. Res., 43, 267-288.

Katz, E. J. (1993), An interannual study of the Atlantic North Equatorial Countercurrent, J. Phys. Oceanogr., 23, 116-123.

Levitus, S., and T. P. Boyer (1994), World Ocean Atlas 1994, vol. 4, Temperature, NOAA Atlas NESDIS 4, 129 pp., Natl. Oceanic and Atmos. Admin., Silver Spring, Md.

Levitus, S., R. Burgett, and T. Boyer (1994), World Ocean Atlas 1994, vol. 3, Salinity, NOAA Atlas NESDIS 3, 111 pp., Natl. Oceanic and Atmos. Admin., Silver Spring, Md.

McCreary, J. P., and P. Lu (1994), On the interaction between the subtropical and the equatorial oceans: The subtropical cell, J. Phys. Oceanogr., $24,466-497$.

Nof, D. (1996), Why are rings regularly shed in the western equatorial Atlantic but not in the western Pacific?, Prog. Oceanogr., 38, 417451 . 
Philander, S. G. H., and R. C. Pacanowski (1986), The mass and heat budget in a model of the tropical Atlantic Ocean, J. Geophys. Res., 91 , $14,212-14,220$

Richardson, P. L., and T. K. McKee (1984), Average seasonal variation of the Atlantic equatorial currents from historical ship-drifts, J. Phys Oceanogr., 14, 1226-1238.

Richardson, P. L., and G. Reverdin (1987), Seasonal cycle of velocity in the Atlantic North Equatorial Countercurrent as measured by surface drifters, current meters, and ship drifts, J. Geophys. Res., 92, 3691-3708.

Richardson, P. L., S. Arnault, S. L. Garzoli, and J. G. Bruce (1992), Annual cycle of the North Equatorial Countercurrent, Deep Sea Res., 39, $997-$ 1014.
Waliser, D. E., and C. Gautier (1993), A satellite-derived climatology of the ITCZ, J. Clim., 6, 2162-2174.

E. J. D. Campos, Laboratório de Modelagem de Processos Oceânicos, Instituto Oceanográfico da Universidade de São Paulo, São Paulo, Brazil.

C. A. Fonseca and G. J. Goni, Atlantic Oceanographic and Meteorological Laboratory, Physical Oceanography Division, NOAA, 4301 Rickenbacker Causeway, Miami, FL 33149, USA. (carlos.fonseca@noaa. gov)

W. E. Johns, Division of Meteorology and Physical Oceanography, Rosenstiel School of Marine and Atmospheric Science, Miami, FL, USA. 